\title{
Aprendizagem Colaborativa Móvel: superando os obstáculos e abraçando as oportunidades
}

\author{
Karla Angélica Silva do Nascimento ${ }^{1}$, José Aires de Castro Filho ${ }^{2}$ \\ ${ }^{1}$ Universidade Federal do Ceará (UFC), Programa de Pós-Graduação em Educação \\ Brasileira, Rua Waldery Uchoa, 01 - Benfica - CEP 60020-110 - Fortaleza - CE \\ ${ }^{2}$ Instituto UFC Virtual - Universidade Federal do Ceará (UFC), Av. Humberto Monte, \\ s/n, bloco 901, 1o andar, Cep:60440-554, CEP 60440-554 - Fortaleza - CE - Brasil \\ $\{$ karla, aires\}@virtual.ufc.br
}

Abstract. The present study aimed to report how mobile devices assisted a teaching practice during the realization of an educational project in and beyond the classroom. The study used a qualitative approach with the use of action research, carried out with a 7th grade science teacher from a Ceará public school. The results show how it is possible to work with different devices when working with school contents in different contexts.

Resumo. O presente estudo objetivou relatar como os dispositivos móveis auxiliaram a prática docente durante a realização de um projeto educativo na $e$ além da sala de aula. O estudo usou uma abordagem qualitativa com o emprego da pesquisa-ação, realizada com uma professora de Ciências do 70 ano do ensino fundamental de uma escola da rede pública do Ceará. Os resultados mostram como é possivel trabalhar com diferentes dispositivos ao trabalhar os conteúdos escolares em diferentes contextos.

\section{Introdução}

Aprendizagem móvel como conceito evoluiu rapidamente e não é mais considerado apenas uma tendência tecnológica ou atraente para os interessados em dispositivos móveis. As discussões recentes tendem a afirmar que houve uma mudança na definição da aprendizagem móvel com base na cultura digital [Santos, 2015; Santaella, 2014], no trabalho colaborativo, nos recursos online usados [Nascimento; Castro Filho, 2017; Miguel et al., 2016; Falloon, 2015; Norris; Soloway, 2015] e na inclusão do contexto formal e informal na educação [Sharples, 2015; Traxler; Crompton, 2015; Almeida; Valente, 2014].

Nessa perspectiva, a sociedade está inserida em uma cultura digital. Para Santaella (2014), as tecnologias do mundo digital criam a potência das ideias coletivas, do pensar junto. É na cultura digital que se distinguem novos processos de produção e acumulação do conhecimento. Por exemplo, estabelecer uma lógica que rompe com a linearidade para dar lugar a uma lógica hipertextual, propiciar condições técnicas infraestruturais para uma comunicação muito mais ágil e interativa e propor interação síncrona e assíncrona entre um número muito maior de pessoas.

Uma das características dessa cultura é a utilização dos dispositivos móveis (netbooks,tablet, smartphones) não somente para acesso às informações, mas também para a produção de novas informações. Nesse sentido, como usar o potencial dessas tecnologias para apoiar professores e alunos na produção colaborativa de 
conhecimentos? Essa é uma questão recorrente ao desafio que as instituições de ensino estão enfrentando desde a chegada desses dispositivos.

Para Liu, Lin e Pass (2014), a mobilidade tem sido considerada uma forma eficaz para apoiar a aprendizagem centrada no aluno, pois pode tornar a aprendizagem mais flexível, personalizada e colaborativa. Os alunos podem aprender em diferentes situações, utilizar recursos diversos e compartilhar suas experiências com seus pares. Os autores atribuem o sucesso à adoção de três fatores: a viabilidade tecnológica de aprendizagem móvel, as necessidades de flexibilidade das atividades e os benefícios pedagógicos relacionados ao compartilhamento e produção entre pares. A aprendizagem móvel acontece quando o aluno tira proveito das oportunidades de aprendizagem oferecidas por meio de dispositivos móveis e quando não está em um local predeterminado.

Esses parâmetros reforçam o estudo sobre como e de que forma a mobilidade transforma situações de aprendizagem, cria oportunidades para além da sala de aula, oferece flexibilidade em relação ao tempo e lugar, facilita a comunicação e interação entre os professores e os alunos, bem como incentiva a aprendizagem colaborativa. Isso pode significar que a tecnologia móvel atua como um catalisador sobre as preferências dos alunos, suas habilidades e seus comportamentos em relação às atividades propostas.

É preciso, portanto, pensar estratégias metodológicas que transformem e valorizem os conhecimentos dos alunos a partir de uma prática colaborativa baseada na mediação docente que permeie abordagens educacionais envolvendo esforço intelectual conjunto.

Assim, este trabalho tem como objetivo compreender como os dispositivos móveis podem auxiliar a prática pedagógica, durante a realização de um projeto educativo na e além da sala de aula envolvendo uma docente e seus discentes. A elaboração deste texto articula o conceito de mobile learning com aprendizagem colaborativa, bem como evidencia a opção pela abordagem qualitativa com o emprego da pesquisa-ação, ao envolver o trabalho colaborativo de uma professora de Ciências. interessada em contribuir com a resolução imediata de preocupações práticas, culturais e sociais nas aulas de Ciências do $7^{\circ}$ ano do ensino fundamental.

\section{Metodologia}

Esta pesquisa foi desenvolvida em uma escola de ensino fundamental do município de Aquiraz, na região metropolitana de Fortaleza, CE. A escola era participante dos Projetos Luzes para Aprender e Edigital, através de uma parceira da Universidade Federal do Ceará (UFC), Companhia Energética do Ceará (COELCE) e Organização dos Estados Ibero-americanos para a Educação, a Ciência e a Cultura (OEI).

A formação docente trabalhada nos dois programas tinha como propósito relacionar os conteúdos, as estruturas pedagógicas dos dispositivos e aplicativos móveis e desenvolver conhecimento básico sobre as diferentes formas de utilização da informática na educação e sua relação com o contexto escolar, possibilitando o uso dessas tecnologias no planejamento de atividades/projetos da escola. Além da formação, a escola recebeu 18 laptops e 10 dispositivos híbridos: tabletenetbook.

Uma das professoras participantes da formação, desenvolveu um projeto educativo, apoiado por diferentes tecnologias. Esses recursos tomaram como base os 
princípios e características da aprendizagem colaborativa móvel durante as suas aulas de Ciências com uma turma de alunos do $7^{\circ}$ ano do Ensino Fundamental.

Para tanto, tal investigação, de caráter qualitativo, esteve diretamente relacionada ao paradigma interpretativo. Entende-se que esse paradigma se centra no estudo dos significados das ações humanas que, no caso deste estudo, levou em consideração as interpretações e construções estabelecidas pela pesquisadora e sujeito investigado, convivendo no contexto que está sendo explorado [Guba; Lincoln, 1994]. Pensando nisso, foi selecionado o método de pesquisa-ação que estimula o docente a questionar suas próprias ideias, teorias, práticas e seus contextos como elementos de análise.

Esse método considera, ainda, que o processo de investigação se realiza no coletivo, em que o tempo e o espaço de reflexão do ato de fazer são referendados pelos próprios participantes da pesquisa. Para isso, foi imprescindível estudar a necessidade formativa docente e oferecer elementos para que suas dificuldades fossem superadas [Barbier, 2004].

Os encontros de formação proporcionaram o conhecimento de recursos educacionais digitais, como também a utilização dos softwares instalados nas máquinas, aplicativos do Google Drive e demais ferramentas disponibilizadas pelos tablets e netbooks da escola. Além disso, foi possível trabalhar com sistemas operacionais diferentes. Esse breve relato retrata o contexto formativo em que a professora participantes iniciou suas primeiras ideias para realização do projeto.

O estudo procurou compreender como os dispositivos móveis auxiliaram a prática pedagógica, durante a realização do projeto que envolvia sustentabilidade e dispositivos móveis, intitulado de "Reflorestamento e Tecnologia Móvel: cuidando da arborização do bosque". O bosque fica ao lado da escola e é também um espaço onde as atividades práticas das aulas de Ciências eram realizadas.

Os objetivos do projeto foram desenvolvidos com base no cuidado e preservação do meio ambiente, nas ações sustentáveis, na utilização de dispositivos móveis para favorecer o ensino, a aprendizagem e a produção coletiva dos alunos e no protagonismo juvenil que colabora para a formação de pessoas mais autônomas e comprometidas socialmente. Devido à facilidade de compartilhamento de materiais digitais nas redes sociais, professora e alunos perceberam que essas tecnologias poderiam ser uma forma de divulgar e sensibilizar a comunidade para ajudá-los no projeto de preservação do bosque.

A coleta de dados neste estudo representou um processo dinâmico realizado pela pesquisadora, tendo como instrumentos: a) entrevistas com a professora; b) observação; c) diário de campo; d) fotografias e áudios. Estes contemplam informações necessárias à investigação para a compreensão da prática docente ao empregar dispositivos móveis no dia a dia da escola.

Todas as atividades do referido projeto foram realizadas com o auxílio de aplicativos baseados em computação em nuvem. Tanto a professora quanto os alunos puderam acessá-los por meio de um navegador web, independente do equipamento ou sistema operacional, armazenando suas informações, fotos, vídeos, links, ou seja, tudo que desejavam manter lá. Esses aplicativos facilitaram a inserção dos dados gerados pelos alunos durante as aulas de campo ou em outras situações de aprendizagem. 
VII Congresso Brasileiro de Informática na Educação (CBIE 2018)

Anais dos Workshops do VII Congresso Brasileiro de Informática na Educação (WCBIE 2018)

\section{Resultados e discussão}

Durante a realização do projeto "Reflorestamento e Tecnologia Móvel: cuidando da arborização do bosque", a professora e sua turma de alunos se depararam com situações diferentes: ora estavam na escola e participavam de tarefas presenciais, ora estavam no contraturno de aula realizando alguma atividade online, seja no bosque, no bairro, com os vizinhos, na praça próxima ao açude ou em casa, registrando com os tablets ou com seus próprios smartphones, utilizando redes sociais e aplicativos para armazenamento de informações em nuvem (GoogleMaps e Drive).

Para desenvolvimento de todas essas ações, foram realizados 20 (vinte) encontros com a professora para execução do projeto com a turma de alunos, assim distribuídos: 10 (dez) aulas de Ciências para a criação do mapa colaborativo do bosque, pesquisa na Internet, registro de fotos, criação colaborativa de planilha eletrônica, análise dos dados coletados e elaboração de um gráfico; 03 (três) aulas de campo para explicar e confrontar os conteúdos teóricos e práticos das aulas; 07 (sete) encontros no contraturno para atividades de filmagem de vídeo, de entrevista, do monitoramento online das plantas e da criação da logomarca do projeto.

Um dos primeiros aplicativos selecionados foi o Google Maps, pois as atividades necessitavam do mapeamento das plantas da região ao entorno da escola. A professora conheceu as possibilidades do aplicativo durante os encontros de formação. Ela se propôs usá-lo também, mas abordando a realidade da comunidade local.

A partir da necessidade de compartilhar informações e produzir colaborativamente, elegeu outros aplicativos do Google Drive: Planilhas para levantamento, comparação e criação de gráfico sobre os tipos de plantas do bosque e Formulários para o monitoramento online.

Conforme Castro Filho (2016), aprender com atividades baseadas na web possibilita diferentes cenários reais e recursos digitais que podem complementar, integrar e organizar os dados gerados pelas pesquisas dos próprios alunos. Os dispositivos móveis não estão restritos aos ambientes internos da escola, a informação virtual pode ser integrada ao ambiente real. O autor ressalta ainda que os alunos têm mais oportunidades de se envolverem nas atividades escolares quando estas são ao ar livre, comparando o que se vê na sala de aula com situações reais do dia a dia.

Todas essas atividades caminharam junto com o plano de curso de Ciências, como também com o planejamento semanal, criando situações reais vividas pelos próprios alunos, revelando seus conhecimentos, buscando envolvê-los em todo o processo. Para Almeida e Valente (2014), as tecnologias móveis podem ajudar a tornar a propagação da informação em um currículo vivo. Para isso, é necessário que o professor crie situações que oportunizem momentos de conversa e compartilhamento, propiciando uma convergência entre o formal, não formal e informal. Essas tecnologias facilitaram a manipulação dos dados gerados pelos alunos, principalmente aqueles demandados de registros fotográficos para comparação e organização dos conceitos explorados na sala de aula (e.g. semelhanças entre as plantas, sua origem, habitat dos animais, seus tipos).

Neste sentido, a professora procurou equilibrar o plano curricular de Ciências, com os problemas reais da comunidade e o uso de dispositivos móveis. Assim, ler, interpretar, conhecer o ambiente e a história, foram objetivos fundamentais do projeto 
VII Congresso Brasileiro de Informática na Educação (CBIE 2018)

Anais dos Workshops do VII Congresso Brasileiro de Informática na Educação (WCBIE 2018)

que com o apoio destes dispositivos oportunizaram a autonomia e a criatividade, ampliaram as possibilidades de aprendizagem e promoveram produções colaborativas.

Na compreensão de Norris e Soloway (2015), as tecnologias móveis, como instrumentos de mediação, oferecem possibilidades de trabalhar com representações virtuais, favorecendo a exploração espontânea e facilitando a autonomia do aluno. Por meio dos recursos textuais e audiovisuais, podem-se agrupar imagens com sons e movimentos, integrando a percepção, o raciocínio e a imaginação, de forma natural, pessoal e dinâmica.

Pensando nisso, os recursos escolhidos pela professora ofereceram possibilidades de mediação na convivência entre os pares, promovendo situações de aprendizagem e interferindo no desenvolvimento dos alunos. Para que as atividades ocorressem a contento, os aplicativos (Google Maps, Formulário, Planilha, Blogger do Drive e Whatsapp) ajudaram a analisar a participação e a criação dos alunos, a partir da realização de suas atividades.

Falloon (2015) revela a necessidade de avaliar os aplicativos antes de serem utilizados com os alunos, principalmente verificar se estes se encaixam nos objetivos de ensino que se quer alcançar e se os estudantes podem utilizá-los de forma autônoma. Para o autor, é possível equilibrar a utilização de aplicativos que promovam interações sociais e estabeleçam configurações específicas de conteúdos curriculares com aplicativos mais voltados para situações lúdicas.

Nas aulas, a professora sempre chamava algum aluno, cuja tela do netbook estava projetada no telão, a fỉm de ajudá-la na explicação operacional de algum aplicativo e na exploração didática da atividade. Enquanto ela pedia para executar uma determinada ação, o aluno fazia a demonstração, os demais prestavam atenção e depois seguiam realizando a atividade nos dispositivos (netbook, tablet e smartphone).

Nas aulas de campo, a professora recomendava à turma que fotografasse as espécies de vegetais e animais, pois em outro momento usaria tais registros para compor o mapa colaborativo sobre o bosque. Os alunos registraram espécies de animais e classificaram em vertebrados e invertebrados. Encontraram lagartas, girinos, várias espécies de formigas, borboletas, aranhas, marimbondos e um soinho (macaco sagui) na parte superior de uma das mangueiras.

Nas aulas seguintes, os alunos apresentavam suas fotos acompanhadas de informações que haviam pesquisado na Internet. Isso também aconteceu ao comparar os tipos e quantidade de plantas existentes no bosque. Na maioria das vezes, os dados foram armazenados nos tablets ou netbooks e depois compartilhados aos demais. Em outras ocasiões os registros estavam nos smartphones dos alunos e anexados no grupo criado no aplicativo Whatsapp.

A vantagem de estar a qualquer hora e em qualquer lugar usando o smartphone favoreceu a realização das atividades. Sharples (2015) destaca que a conectividade pode promover diferentes redes de aprendizagem, porque ela deixa de ser uma atividade interna, individualista para se tornar uma atividade externa e colaborativa. $O$ autor reforça que a conectividade pode trazer benefícios na era digital. Entretanto, o sistema educativo tem demorado a reconhecê-la.

Enquanto a professora explicava a necessidade de registrar por meio de fotos as plantas do bosque, de classificar e de pesquisar seus nomes científicos, os alunos 
compartilhavam fotografias e informações através de Bluetooth ou anexavam no grupo do Whatsapp. Esse compartilhamento de informações foi tão naturalmente interiorizado pela professora que ela nem se deu conta que estava usando de maneira diferente daquilo que fazia antes desta experiência, por exemplo: imprimir ou digitalizar as imagens, fotocopiá-las e distribuí-las aos alunos (Diário de campo).

Nascimento e Castro Filho (2017) revelam que a mobilidade e conectividade dos dispositivos móveis na educação podem permitir que os estudantes se tornem participantes ativos e não receptores passivos. No entanto, é relevante explicar que a professora os instigou a explorar diferentes situações educacionais. Isso oportunizou autonomia e sensibilidade ao tirar proveito das oportunidades de aprendizagem oferecidas pela tecnologia móvel, neste caso, pelosmartphone.

Para a professora, o celular deve ser usado com muita responsabilidade no contexto escolar, já que se trata de um dispositivo pessoal com diversas funcionalidades e configurações. Nicolau et al. (2017) sugerem que os professores estabeleçam quando e onde os alunos podem usá-lo. Os contratos sociais podem ser desenvolvidos como um acordo para definir como, quando, porque e onde esse equipamento pode ser usado na sala de aula.

Com uma variedade de recursos disponíveis na Internet, os dispositivos móveis ofereceram opções que ampliam o processo de ensino e aprendizagem, tanto no acesso quanto na produção de conteúdos a qualquer hora e lugar. Todavia, o investimento da aprendizagem móvel depende muito do nível de aceitação social que recebe. Sharples (2015) reforça quatro características de aprendizagem com dispositivos móveis: são usadas em todos os lugares; possuem aplicativos amigáveis e pessoais; são baratos e fáceis de usar; e, podem ser usadas em todas as esferas da vida.

Neste sentido, Traxler e Crompton (2015) ressaltam que essas tecnologias chamam atenção para os efeitos da mobilidade na inclusão de novas formas de dividir os próprios limites de tempo e espaço das aulas. Com base neste raciocínio, a professora combinou com o responsável pelo laboratório de informática da Escola que seus alunos do $7^{\circ}$ ano podiam usar os netbooks e tablets no contraturno, desde que não atrapalhassem as aulas dos professores que tinham agendado o uso de tais dispositivos com suas turmas.

Para a professora estes dispositivos facilitaram a organização, o compartilhamento da informação e aproximou os conteúdos curriculares à realidade dos alunos seja na sala de aula, no campo, em casa ou em outro lugar, ela justifica:

A gente é móvel, os alunos principalmente [Risos]. Eles são inquietos não conseguem ficar muito tempo em um só lugar. Com a tecnologia móvel, os alunos puderam se locomover para ajudar os colegas, levar de um canto para outro, isso facilita a interação. Senti que eles se agruparam melhor, produziram várias coisas de forma colaborativa e depois compartilhavam a todo instante (Entrevista).

A professora deixava os alunos à vontade para fotografar, enviar vídeos, músicas ou responder os itens do formulário feito no Google Drive. Como os aplicativos compartilhados poderiam ser acessados em qualquer tempo e lugar, os alunos também usaram os horários no contraturno de aula para participar respondendo ou registrando 
algo. Ela também percebeu que o fato de os alunos levarem seus smartphones para registrar suas observações a qualquer hora foi um elemento motivador e que eles mesmos demandavam critérios de exigências em relação a produção final dessa atividade e do mapa colaborativo do bosque.

A utilização do Google Mapsna prática escolar precisou ser mediada pela docente, promovendo momentos de reflexão durante a ação colaborativa, já que sua plataforma proporciona trabalho coletivo. Quando o aluno A criava um marcador e inseria um texto usando um determinado netbook, o aluno $\mathrm{B}$, em outro equipamento, ajudava-o a inserir outros elementos. Para isso, os estudantes refletiam, discutiam a melhor forma de inserir as informações e tomavam decisões de fazê-las em conjunto (Diário de campo). Constatou-se que esse aplicativo é também um espaço de aprendizagem que utiliza ferramentas online como instrumentos de reflexão do conhecimento.

Ao usar tecnologias móveis na educação, a colaboração, para Miguel et al. (2016), é o elemento mais importante do processo, já que remete ganhos de produtividade, flexibilidade no acesso físico, na captação e integração de dados. Esses autores também ressaltam que ao agregar a conexão de rede sem fio, essas tecnologias podem solucionar fragilidades de coordenação, comunicação, organização, interação e mobilidade encontradas na aprendizagem colaborativa desenvolvida sem tais recursos.

A aprendizagem colaborativa móvel, nesta pesquisa, estimulou a interação dos alunos face à mediação docente na Escola, bem como foi uma proposta pedagógica trabalhada para ensinar e aprender utilizando diferentes dispositivos móveis durante as aulas. Essa proposta assume que o acompanhamento contínuo é um elemento importante para verificar o processo de mudança dos alunos na realização de atividades menos complexas para as mais complexas [Sharples, 2015].

Seguindo os fatores citados acima, o foco dessa aprendizagem não é o professor, os alunos e nem as tecnologias, mas a interação comunicativa realizada entre esses três elementos. Em um primeiro nível, a mobile learning tenta compreender as pessoas e os dispositivos móveis em fluxo contínuo através de ambientes dinâmicos que podem ser locais ou virtuais. Em segundo plano, ela avalia o ensino e a aprendizagem como um processo de conversação dentro de contextos diferentes que permitem compartilhamento, negociação de ideias e produção colaborativa. Portanto, todos esses aspectos foram observados e analisados nas atividades que a professora desenvolveu com sua turma de alunos durante o projeto.

As experiências do referido projeto foram divulgadas nas redes sociais, repercutindo positivamente as ações da professora e dos alunos envolvidos. Durante e após o término do projeto, duas TV locais ${ }^{1}$ gravaram matérias sobre os resultados e as conquistas do projeto. Devido os feeds de notícias compartilhados no Facebook de alguns alunos e da escola, eles conheceram melhor as atividades, os dispositivos móveis utilizados pela professora e como se deu o envolvimento dos alunos.

\section{Conclusão}

Diante do objetivo proposto, foi possível compreender as conquistas, os desafios e as dificuldades de combinar diferentes dispositivos móveis (pedagógicos, técnicos e funcionais) com propostas de atividades que ultrapassaram as paredes da sala de aula. Estes

\footnotetext{
${ }^{1}$ TV Verdes Mares e TV Diário.
} 
dispositivos agregaram várias mídias, possibilitando, entre os alunos, produção colaborativa com alto potencial para comparar, vivenciar e transformar os conteúdos estudados na sala de aula em situações reais, próximas do dia a dia.

Percebeu-se ainda que esses dispositivos estreitaram o fosso existente entre o que se aprende na sala de aula e o que se vê nas ruas, no bairro, na comunidade. Diante da proposta de criação do mapa colaborativo, os alunos pareceram entusiasmados com as atividades, porém muitos deles esperaram inspiração e estímulo docente.

Em paralelo, trabalhar com aplicativos baseados em computação em nuvem significou o rompimento da desarticulação entre o currículo e a realidade, isto observado nos registros das atividades por meio dos aplicativos em qualquer tempo e espaço. É importante articular os saberes escolares com os saberes sociais de forma que o estudante contextualize o que se aprende e não reforce algo abstrato ou fragmentado sem sentido.

Infere-se que, durante o processo de apropriação da professora, alguns fatores sociais e culturais exerceram influência sobre como essas tecnologias são adotadas e usadas, uma vez que a Escola havia sido contemplada com dispositivos móveis (netbook e tablet). Depois de ter explorado as potencialidades dos dispositivos móveis na formação, a professora descobriu os seus benefícios, suas utilidades e passou a usá-las também como recurso educativo, integrando-as nas suas práticas educativas diárias.

Assim, a formação docente para selecionar, testar e avaliar a utilização dos dispositivos móveis de maneira responsável e apropriada aos objetivos educativos, apoiando e articulando os conteúdos curriculares às produções colaborativas entre os alunos, é imprescindível.

Certamente, há muita coisa a fazer nesta área. Sugere-seinvestigar aplicativos que proporcionem produções individuais ou colaborativas, diversificadas ou integradas, que promovam a negociação de ideias, o estímulo à criatividade, a visão crítica e reflexiva de uma determinada ação educativa. Além disso, é importante pensar no planejamento dos objetivos pedagógicos de sua utilização e no investimento de conexão sem fio de qualidade.

\section{Referências}

Almeida, Maria Elizabeth Bianconcini de; Valente, José Armando. Currículo e Contextos de Aprendizagem: integração entre o formal e o não formal por meio de tecnologias digitais. Revista Cientifica e-Curriculum, v. 12, n. 2, p. 1162-1188, 2014.

Barbier, René. A pesquisa-ação. Brasília: Líber Livro Editora, 2004.

Castro Filho, J. A. de. Formação Docente na Era da Cibercultura. Revista Tecnologias na Educação. Ano 8. Número/Vol.16. Edição Temática. Congresso Regional sobre Tecnologias na Educação (Ctrl+E 2016). Setembro 2016.

Ceará. Lei $\mathrm{N}^{\mathrm{o}} 14.146$, de 25 de junho de 2008. Dispõe sobre a proibição do uso de equipamentos de comunicação, eletrônicos e outros aparelhos similares, nos estabelecimentos de ensino do Estado do Ceará, durante o horário das aulas. Diário Oficial, Ceará, CE, 30 set. 2008.

Elliot, John. El cambio educativo desde lainvestigación-acción. Madrid: Morata, 1993. 
VII Congresso Brasileiro de Informática na Educação (CBIE 2018)

Anais dos Workshops do VII Congresso Brasileiro de Informática na Educação (WCBIE 2018)

Falloon, Garry. What's the difference? Learning collaboratively using iPads in conventional classrooms. Computers \& Education, v. 84, p. 62-77, 2015.

Miguel, J.; Caballé, S.; Xhafa, F.; Prieto, J.; Barolli, L. A methodological approach for trustworthiness assessment and prediction in mobile online collaborative learning. Computer Standards \& Interfaces, v. 44, p. 122-136, 2016.

Nascimento, Karla Angélica Silva do; Castro Filho, José Aires de. Abordagens Pedagógicas $\mathrm{Na}$ Literatura Sobre A Aprendizagem Móvel No Ensino Fundamental. Holos, v. 8, p. 191-204, 2017.

Nicolau, R. M.; Marinho, Simão Pedro P.; Marinho, A. M. S. Tecnologias digitais móveis na Educação Básica: nem tanto ao céu, nem tanto ao inferno. In: Congresso Brasileiro de Informática na Educação - CBIE 2017 - WTME, 2017, Recife. Anais dos Workshops do Congresso Brasileiro de Informática na Educação. Porto Alegre: Sociedade Brasileira de Computação, 2017. v. 1. p. 564-573.

Norris, Cathleen A.; Soloway, Elliot. Mobile technology in 2020: Predictions and implications for K-12 education. Educational Technology, v. 12, p. 12-18, 2015.

Santaella, Lucia. Comunicação ubíqua: repercussões na cultura e na educação. Pia Sociedade de São Paulo-Editora Paulus, 2014.

Santos, Edméa. A mobilidade cibercultural: cotidianos na interface educação e comunicação. Em Aberto, v. 28, n. 94, 2015.

Sharples, Mike. Making sense of context for mobile learning. In: Mobile Learning. Routledge, 2015. p. 154-167.

Traxler, John M.; Crompton, Helen. Mobile Learning. In: Encyclopedia of Mobile Phone Behavior. IGI Global, 2015. p. 506-518. 